NOTA

\title{
INFLUÊNCIA DA DESIDRATAÇÃO NA RECUPERAÇÃO DA FIRMEZA E NA BROTAÇÃO EM CENOURA ${ }^{(1)}$
}

\author{
ADONAI GIMENEZ CALBO ${ }^{(2)}$
}

\section{RESUMO}

Raízes de cenoura Daucus Carota L. Brasília recém-colhidas foram submetidas a diferentes níveis de desidratação com emprego de ventilação forçada a $25 \pm 2{ }^{\circ} \mathrm{C}$. Sob teores relativos de água inferiores a 0,95 a firmeza dependente da pressão celular, medida com a técnica da aplanação, ficou reduzida a praticamente zero, ao passo que as raízes do tratamento controle tiveram firmeza acima de $7,0 \mathrm{kgf} \mathrm{cm}^{-2}$. Após o armazenamento em sacos plásticos de polietileno de baixa densidade, durante 67dias a $5 \pm$ $2{ }^{\circ} \mathrm{C}$, as raízes que tiveram seu teor relativo de água reduzido a menos de 0,75 recuperaram a firmeza em mais de $60 \%$ da turgescência inicial do controle, além de apresentarem brotação. A recuperação da firmeza ocorreu sem absorção de água, visto que o armazenamento em embalagens de plástico diminuiu mas não anulou a transpiração. Essa recuperação da firmeza e a posterior brotação contrariou a expectativa inicial de que as raízes murchas não brotariam. Duas hipóteses foram postuladas para explicar esses resultados: a primeira seria o envolvimento de um processo de redistribuição de água na raiz; a segunda, a redução do volume do órgão, de acordo com a teoria coesiva do encolhimento celular. A favor da primeira hipótese pesou a formação de pequenas lacunas lisógenas distribuídas a partir do centro do cilindro vascular. $\mathrm{O}$ volume total dessas cavidades lisógenas corresponderia a uma quantidade de água aparentemente inferior a $2 \%$ do volume da raiz, a qual seria insuficiente para explicar a recuperação da firmeza em raízes que perderam mais de $20 \%$ de seu conteúdo de água. Fica a possibilidade de haverem outras causas não percebidas de redistribuição de água ou que, de fato, a presumida redução plástica do volume das células - de acordo com a teoria coesiva do encolhimento celular - tenha ocorrido.

Palavras-chave: armazenamento, crescimento, Daucus carota L., encolhimento, firmeza, hidratação, redução de volume, turgescência.

\section{ABSTRACT DEHYDRATION, FIRMNESS AND CARROT SPROUTING}

'Brasília' carrot roots (Daucus carota L.) have been exposed to different dehydration levels through the use of forced ventilation at $25 \pm 2{ }^{\circ} \mathrm{C}$. At relative water content smaller than 0.95 , the turgor-dependent firmness, measured by the external force method, has been reduced to nearly zero, control roots had a firmness above $7.0 \mathrm{kgf} \mathrm{cm}^{-2}$. After a 67 day storage at $5 \pm 2{ }^{\circ} \mathrm{C}$, roots that had their initial relative water contents reduced to less than 0.75 , presented a firmness recovery to more than $60 \%$, as compared with that of the control roots, in addition showing significant sprouting. These levels of firmness recovery and sprouting had not been previously described. Two hypothesis have been put forward to explain those results: a) occurrence of water relocation process in the roots; b) the theory of cellular cohesive shrinkage. The formation of small lisogenous cavities would favor the first hypothesis; however, accounting for less than $2 \%$ of the root volume, they would not be enough to

(1) Trabalho recebido para publicação em 9 de agosto de 1999 e aceito em 28 de março de 2000.

(2) Embrapa-Hortaliças, Caixa Postal 0218, 70359-970 Brasília (DF). E-mail: adonai@cnph.embrapa.br 
explain the firmness recovery observed in roots with water volume reduction above $20 \%$. By exclusion, it seems that cellular cohesive shrinkage has been the main factor in the firmness recovery observed, allowing significant sprouting in dry roots.

Key words: Daucus carota L., firmness, growth, hidration, shrinkage, storage, turgor, volume reduction.

\section{Introdução}

As raízes de cenoura tornam-se flácidas logo após desidratações rápidas que causam redução do teor relativo de água para níveis abaixo de $95 \%$. Nesse caso, a firmeza dependente de turgescência medida pela técnica de aplanação, na cenoura reduz-se a praticamente zero (CAlbo e Calbo, 1989; Calbo e Nery 1995).

Entretanto podem as mesmas recuperar a firmeza e brotar sem absorção adicional de água, de acordo com um processo biológico ainda em estudo, anteriormente descrito para folhas de repolho (LEvITT, 1986; WeIsz et al., 1988). O senso comum sugere que as raízes murchas sejam desprezadas, a partir da hipótese presumida de que não recuperariam a firmeza nem brotariam. Neste trabalho verifica-se se essas hipóteses são ou não verdadeiras.

\section{Material e Métodos}

Raízes de cenoura $c v$ Brasília recém-colhidas tiveram a sua parte aérea cortada com tesoura. As raízes muito grandes, pequenas ou com defeitos foram eliminadas, e 49 parcelas de 10 raízes foram amostradas ao acaso. Em oito repetições aplicaram-se desidratações correspondentes a perdas de umidade na matéria fresca, de $0 \%, 3 \%, 6 \%, 9 \%, 16 \%$ e $23 \%$. Para a aplicação dos tratamentos as raízes foram distribuídas em camada única, sobre uma bancada, e desidratadas sob ventilação forçada com ar a $25 \pm 2{ }^{\circ} \mathrm{C}$, sob umidade relativa de cerca de $60 \%$. Cada raiz foi repetidamente pesada até alcançar a massa correspondente ao seu tratamento e todas foram colocadas em sacos de polietileno (100 $\mu \mathrm{m}$, baixa densidade), nos quais foram armazenadas, seguindo um delineamento inteiramente casualizado. As embalagens foram posteriormente acopladas ao sistema de armazenamento plastivácuo, com um fluxo de ar da ordem de $100 \mathrm{~mL} / \mathrm{h}$ (CALBO, 1988) e armazenadas em câmara fria, a $5 \pm 2{ }^{\circ} \mathrm{C}$.

Ao final do experimento foram amostradas, ao acaso, 20 raízes de cada tratamento para avaliação da firmeza, pela técnica de aplanação (CALBO e CALBO, 1989; CAlbo e NerY, 1995). Para avaliação da porcentagem de raízes brotadas, cada raiz foi classificada como brotada ou não. $\mathrm{O}$ fato de uma raiz não haver ainda iniciado a brotação após 67 dias de estudo foi tomado apenas como evidência de maior dormência, visto que não se excluiu a possibilidade de a raiz brotar.

Chamou-se, arbitrariamente, de teor relativo de água a razão entre a quantidade de água na raiz desidratada e a quantidade de água da raiz antes de se aplicar o tratamento. Esse teor foi calculado de acordo com a matéria fresca inicial $(1.158,4 \mathrm{~g})$ e a matéria seca inicial $(124,0 \mathrm{~g})$ da quadragésima nona parcela de 10 raízes. A simplificação fez com que o teor relativo de água ficasse superestimado sistematicamente (@1\%), em comparação com o teor relativo de água avaliado pelo método tradicional (SLAVIK, 1974).

\section{Resultados e Discussão}

De maneira surpreendente as raízes de cenoura 'Brasília', desidratadas a teores relativos de água de até $77 \%$, recuperaram em mais de $60 \%$ a firmeza inicial (antes da desidratação) (figura 1), durante 67 dias de armazenamento a $5{ }^{\circ} \mathrm{C}$ sob umidade relativa de quase $100 \%$. Essa recuperação da firmeza dependente da turgescência celular sem absorção de água é ainda um fenômeno pouco compreendido, anteriormente descrito para folhas de repolho por LeVITT (1986) e WeIsz et al. (1988).

Durante o armazenamento as raízes de cenoura desidratadas não só recuperaram a turgescência, como também foram capazes de brotar (figura 2). Tendo em vista os resultados de outras espécies mesofíticas, esperava-se que as raízes de cenoura morressem

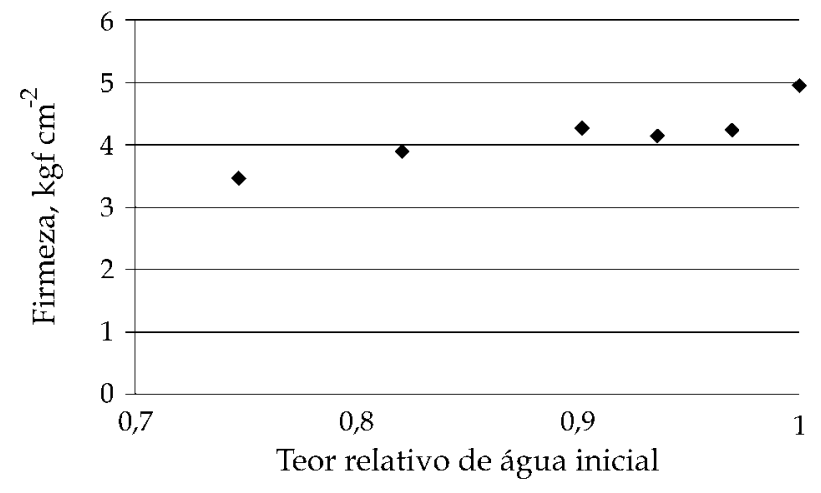

Figura 1. Firmeza medida pela técnica de aplanação de raízes de cenoura 'Brasília', armazenadas por 67 dias a $5{ }^{\circ} \mathrm{C}$ sob umidade relativa do ar superior a $99 \%$. Cada ponto representa a média de 20 repetições. 


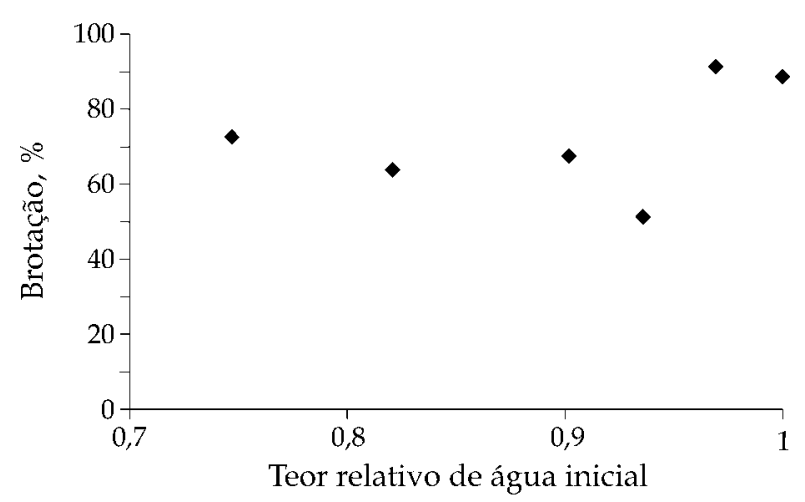

Figura 2. Brotação de raízes de cenoura 'Brasília' submetidas a diferentes níveis de perda de água antes de serem armazenadas por 67 dias a $5^{\circ} \mathrm{C}$, sob umidade relativa do ar superior a $99 \%$. Cada ponto representa a porcentagem de brotação em amostras agrupadas de 80 raízes.

sob a ação de desidratações muito inferiores àquelas aplicadas neste estudo.

O mecanismo de recuperação da turgescência celular sem absorção adicional de água, o qual permitiu inclusive a brotação de raízes, é um fenômeno pouco conhecido e compreendido. Duas hipóteses foram postuladas para explicar tal comportamento da cenoura. Na primeira, sugere-se uma redistribuição da água a partir da formação lisógena de cavidades no cilindro vascular da raiz. Na segunda, sugere-se uma redução plástica do volume do órgão, conforme postulado na teoria coesiva do encolhimento celular desenvolvida por CALBo e PESSOA (1994). De acordo com essa teoria, o encolhimento celular permitiria a recuperação da firmeza, o alívio substancial do estresse hídrico e o aumento do potencial da água da raiz.

A favor da hipótese lisógena de redistribuição de água pode-se argumentar que a formação de pequenas lacunas lisógenas de coloração esbranquiçada, distribuídas a partir do centro do cilindro vascular, conforme A.A. NerY(3) (1995), permitiu a migração de quantidades suficientes de água para as células sobreviventes que puderam, assim, recuperar a turgescência. Todavia, para que esse argumento fosse válido, a quantidade de cavidades formadas no interior da raiz deveria ser volumetricamente similar à quantidade de água perdida pela raiz. No entanto, a inspeção visual de áreas esbranquiçadas no interior de raízes desidratadas, feita por A.A. NerY(3) (1995), sugere que a quantidade de água liberada nesse processo não deve ser maior que $2 \%$. Novos ensaios precisariam ser conduzidos com o emprego de métodos de medição de volumes intercelulares para quantificar os volu-

(3) A.A. Nery. Informação pessoal, 1995. mes de água liberados pela formação lisógena de cavidades.

A segunda hipótese envolve a teoria coesiva do encolhimento celular (CAlbo e PessoA, 1994). De acordo com essa teoria, a variação plástica do volume celular (crescimento ou encolhimento) é dada por uma equação do tipo:

$$
\frac{1}{\mathrm{~V}} \frac{\mathrm{dV}}{\mathrm{dt}}=\Gamma\left(\mathrm{p}_{\mathrm{r}}-\mathrm{z}\right)
$$

em que $\mathrm{V}$ é o volume da planta, $\mathrm{t}$ é o tempo, $\Gamma$ é a extensibilidade ou compressibilidade intrínseca da parede celular, $p_{r}$ é a pressão resultante na matriz da parede celular e z é um limiar de distensão ou compressão que ocorre em paredes viscoelásticas.

Quando as raízes de cenoura foram desidratadas a teores relativos de até $80 \%$ a tensão da água no apoplasma, medida com a câmara de pressão, atingiu valores menores que -2,0 MPa (CALBO e CALBO, 1989). Logo após a desidratação, a pressão de turgescência avaliada pela técnica de aplanação ficava reduzida a praticamente zero. Nessa situação a compressão resultante na parede celular é, em conseqüência, a própria tensão da água medida com a câmara de pressão, i.e., -2,0 MPa. Se o limiar de compressão z fosse - $0,5 \mathrm{MPa}$, então as células deveriam encolher-se no decorrer do tempo, de acordo com a inclinação ou a compressibilidade $\Gamma$.

Se após dois meses de armazenamento a pressão de turgescência celular já estivesse estabilizada, isto é, o encolhimento relativo já houvesse sido reduzido a zero $(\mathrm{dV} / \mathrm{V}=0)$, então $\mathrm{z}$ seria igual a $\mathrm{p}_{\mathrm{r}}$. $\mathrm{O}$ termo $\mathrm{p}_{\mathrm{r}}$ relaciona-se à turgescência $\left(\mathrm{P}_{\mathrm{S}}\right)$ e à tensão da água no apoplasma $\left(\mathrm{P}_{\mathrm{A}}\right)$, pela expressão:

$$
p_{r}=\left(P_{A}+\frac{P_{S} A_{S}}{A_{A}}\right)
$$

onde: $A_{S}$ é a área de simplasma em corte transversal e $A_{A}$ é a área do apoplasma, no mesmo corte. Assim, de acordo com a teoria coesiva do encolhimento celular, pode-se escrever que:

$$
P_{S}=\left(z-P_{A}\right) \frac{A_{A}}{A_{S}}
$$

Ao final do ensaio a pressão celular estimada com a técnica de aplanação assumiu valores da ordem de $0,35 \mathrm{MPa}$ para as raízes desidratadas até o teor relativo de água, da ordem de $75 \%$. Se $\mathrm{A}_{\mathrm{A}} / \mathrm{A}_{\mathrm{S}}=6,16$, como foi estimado por CALBO e CALBO (1989) para raízes de cenoura 'Brasília', então o valor estimado da tensão final da água na planta $\left(\mathrm{P}_{\mathrm{A}}\right)$ seria $-1,07 \mathrm{MPa}$. Em outras palavras, o estresse hídrico ao qual a raiz ficou 
submetida teria sido reduzido para menos da metade do estresse hídrico inicial.

Uma evidência da teoria coesiva do encolhimento celular foi a demonstração do encolhimento de paredes celulares isoladas de centeio, sob a ação de tensões de água induzidas por polietileno glicol 6.000 (EDELMANN, 1995), um agente osmótico de dimensões moleculares suficientes para ser excluído dos poros da parede celular. Baseado nesses resultados, o autor sugeriu que o crescimento celular seria controlado não apenas pela turgescência mas também pela tensão da água no apoplasma.

A descoberta biológica relevante, no presente estudo, foi a observação da recuperação da firmeza e da capacidade de brotação de raízes murchas pela desidratação a teores relativos de até $75 \%$ durante o armazenamento a $5{ }^{\circ} \mathrm{C}$ sem absorção adicional de água. Constatou-se que, em futuro próximo, será possível determinar o limiar de compressibilidade da parede celular - para cenoura 'Brasília' - com a teoria coesiva do encolhimento celular, de Calbo e Pessoa (1994). Para isso os dados necessários serão: a tensão da água no apoplasma, a qual poderá ser medida com uma câmara de pressão no início e no final do ensaio; acompanhamento da recuperação da firmeza das raízes com a técnica de aplanação; medições de pressão de turgescência celular com a sonda de pressão; e o mais difícil, porém possível, melhor estimativa de $\mathrm{A}_{\mathrm{A}} / \mathrm{A}_{\mathrm{S}}$, a qual poderá ser feita por métodos físicoquímicos ou anatômicos. Fica também a possibilidade de avaliação da relevância da formação de cavidades lisógenas no cilindro vascular das raízes de cenoura, como fonte de água para o alívio do estresse hídrico.

\section{Referências Bibliográficas}

CALBO, A.G. Plastivácuo. Horticultura Brasileira, Brasília, v.6, n.1, p.48, 1988. (Resumo)

CALBO, A.G.; CALBO, M.R.E. Medição e importância do potencial de parede. Revista Brasileira de Fisiologia Vegetal, Londrina, v.1, n.1, p.41-46, 1989.

CALBO, A.G.; NERY, A.A. Medida de firmeza em hortaliças pela técnica de aplanação. Horticultura Brasileira, Brasília, v.3, n.1, p.14-18, 1995.

CALBO, A.G.; PESSOA, J.D.C. A plant growth re-analysis. Revista Brasileira de Fisiologia Vegetal, Londrina,v.6, n.2, p.83-89,1994.

EDELMANN, H.G. Water potential modulates extensibility of rye coleoptile cell walls. Botanica Acta, Stuttgart, v.108, p.374-380, 1995.

LEVITT, J. Recovery of turgor by wilted, excised cabbage leaves in the absence of water uptake. Plant Physiology, Rockville, v. 82 n.1, p.147-153, 1986.

SLAVÍK, B. Methods of studying plant water relations. New York: Springer-Verlag, 1974. 449p.

WEISZ, P.R.; RANDALL, H.C.; SINCLAIR, T.R. Water relations of turgor recovery and restiffening of wilted cabbage leaves in the abscence of water uptake. Plant Physiology, Rockville, v. 91, p.433-443, 1988. 